\section{A) Check for updates}

Cite this: Dalton Trans., 2021, 50, 587

\title{
Structural analysis of five-coordinate aluminium (salen) complexes and its relationship to their catalytic activity $\dagger$
}

\author{
Heather Fish, Sam Hart, Katie J. Lamb, (D) Michael North, (D)* Sophie C. Z. Quek, \\ Adrian C. Whitwood, (D) Barnaby Woods and Xiao Wu
}

\begin{abstract}
The crystal structure of $\left[\mathrm{Al}\left({ }^{t} \mathrm{Bu} \text {-salen }\right)\right]_{2} \mathrm{O} \cdot \mathrm{HCl}$ shows major changes compared to that of $\left[\mathrm{Al}\left({ }^{\mathrm{t}} \mathrm{Bu}-\mathrm{salen}\right)\right]_{2} \mathrm{O}$. The additional proton is localized on the bridging oxygen atom, making the aluminium atoms more electron deficient. As a result, a water molecule coordinates to one of the aluminium atoms, which becomes six-coordinate. This pushes the salen ligand associated with the six-coordinate aluminium ion closer to the other salen ligand and results in the geometry around the five-coordinate aluminium atom becoming more trigonal bipyramidal. These results experimentally mirror the predications of DFT calculations on the interaction of $\left[\mathrm{Al}\left({ }^{\mathrm{t}} \mathrm{Bu} \text {-salen) }\right]_{2} \mathrm{O}\right.$ and related complexes with carbon dioxide. Variable temperature NMR studies of protonated $\left[\mathrm{Al}\left({ }^{t} \mathrm{Bu} \text {-salen) }\right]_{2} \mathrm{O}\right.$ complexes revealed that the structures were dynamic and could be explained on the basis of an intramolecular rearrangement in which the non-salen substituent of a five-coordinate aluminium( ${ }^{t} \mathrm{Bu}$-salen) unit migrates from one face of a square based pyramidal structure to the other via the formation of structures with trigonal bipyramidal geometries. Protonated $\left[\mathrm{Al}\left({ }^{\mathrm{t}} \mathrm{Bu}-\right.\right.$ salen) $]_{2} \mathrm{O}$ complexes were shown to have enhanced Lewis acidity relative to $\left[\mathrm{Al}\left({ }^{\mathrm{t}} \mathrm{Bu} \text {-salen) }\right]_{2} \mathrm{O}\right.$, coordinating to water, dioxane and 1,2-epoxyhexane. Coordinated epoxyhexane was activated towards ringopening, to give various species which remained coordinated to the aluminium centers. The protonated $\left[\mathrm{Al}\left({ }^{\mathrm{B}} \mathrm{Bu} \text {-salen }\right)\right]_{2} \mathrm{O}$ complexes catalysed the synthesis of cyclic carbonates from epoxides and carbon dioxide both in the presence and absence of tetrabutylammonium bromide as a nucleophilic cocatalyst. The catalytic activity was principally determined by the nature of the nucleophilic species within the catalyst structure rather than by changes to the Lewis acidity of the metal centers.
\end{abstract}

Received 16th October 2020, Accepted 15th December 2020

DOI: $10.1039 / \mathrm{dOdt03598j}$

rsc.li/dalton planar, but rather adopt stepped and bowl conformations, giving four potentially interconverting conformations as shown in Fig. 2A. ${ }^{3}$ Any substituents on the diamine derived part of the salen ligand ( $\mathrm{R}^{1}$ in Fig. 1 ) can then adopt axial or equatorial positions within the 5 -membered chelate ring (Fig. 2B).

A metal ion coordinated to a salen ligand is most commonly six-coordinate with two additional ligands ( $\mathrm{X}$ and $\mathrm{Y}$ ) also coordinated to the metal to give an octahedral geometry. However, depending on the metal and its oxidation state, fourcoordinate $^{4}$ and five-coordinate ${ }^{5}$ complexes can also be formed and for larger metals, higher coordination-numbers

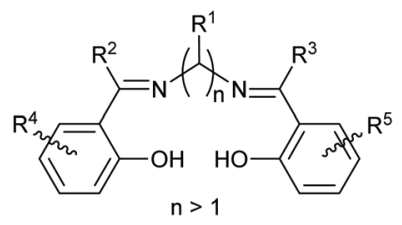

Fig. 1 General structure of salen ligands.
Department of Chemistry, University of York, Heslington, York, YO10 5DD, UK. E-mail: michael.north@york.ac.uk

$\dagger$ Electronic supplementary information (ESI) available: X-ray data and copies of all recorded and simulated spectra. CCDC 2022416. For ESI and crystallographic data in CIF or other electronic format see DOI: 10.1039/d0dt03598j 


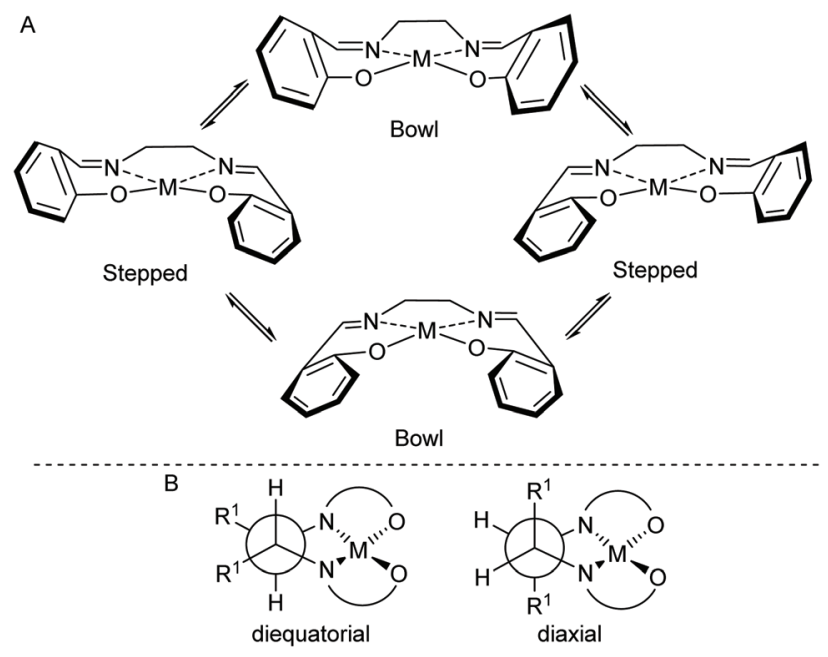

Fig. 2 (A) Stepped and bowl conformations of a salen ligand within a metal(salen) complex. (B) Illustration of substituents $\left(R^{1}\right)$ in axial or equatorial positions.

are possible. ${ }^{6}$ Within an octahedral, six-coordinate salen complex, there are three theoretically possible configurations for the salen ligand: trans, $c i s-\alpha$ and $c i s-\beta$ as shown in Fig. $3 .^{7}$ The trans-configuration is by far the most common, but in complexes composed of a salen ligand and a bidentate ligand, the salen ligand adopts the cis- $\beta$ configuration. ${ }^{8}$ Complexes with a trans-configuration are achiral whilst complexes with cis- $\alpha$ or $c i s-\beta$ configurations are inherently chiral, giving rise to $\Delta$ and $\Lambda$ stereoisomers. ${ }^{7}$

In recent years, we have worked extensively on five-coordinate aluminium complexes of salen and related ligands, showing that complexes 1-5 (Fig. 4) formed active catalysts for: the synthesis of cyclic carbonates from epoxides and carbon dioxide $^{9-12}$ (Scheme 1A); the synthesis of oxazolidinones from epoxides and isocyanates ${ }^{13}$ (Scheme $1 \mathrm{~B}$ ) or from aziridines and carbon dioxide ${ }^{14}$ (Scheme 1C); the synthesis of di- and trithiocarbonates from epoxides and carbon disulfide ${ }^{15}$ (Scheme 1D) and asymmetric cyanohydrin synthesis $^{16}$ (Scheme 1E). Complex 1 has also been used by other researchers to catalyse Michael additions ${ }^{3}$ (Scheme $1 \mathrm{~F}$ ) and Passerinitype reactions ${ }^{17}$ (Scheme 1G). Aluminium(salen) complexes in
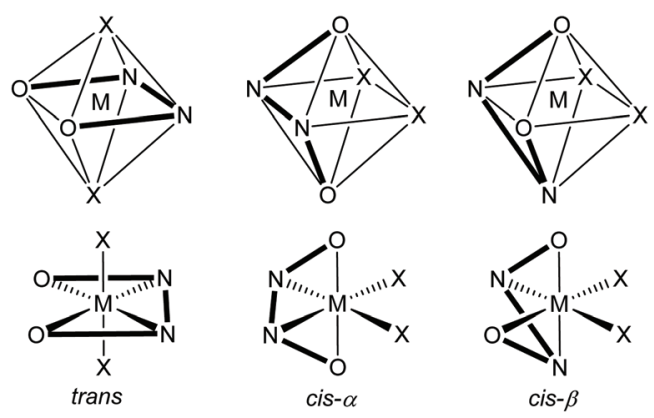

Fig. 3 Potential configurations of six-coordinate, octahedral metal (salen) complexes.
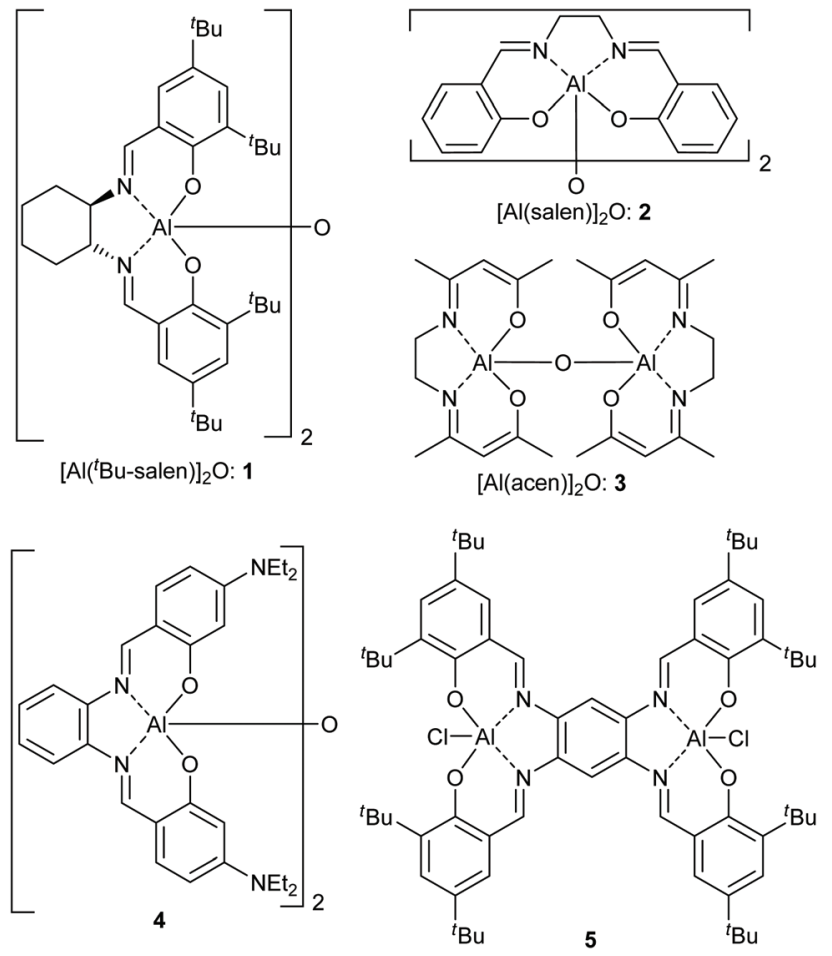

Fig. 4 Structures of five-coordinate aluminium complexes 1-5.
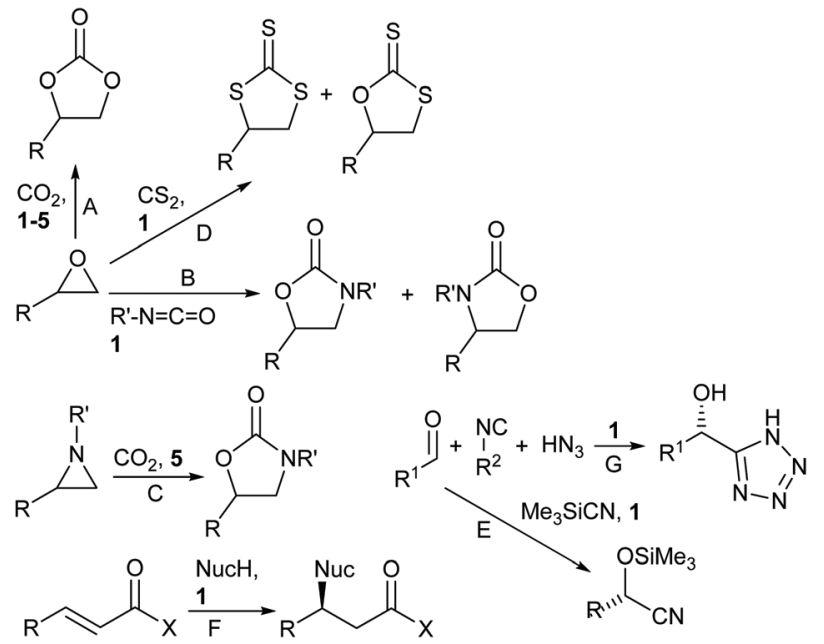

Scheme 1 Reactions catalysed by complexes 1-5.

general have been widely used to initiate ring-opening polymerisation of cyclic esters. ${ }^{18}$

In contrast to six-coordinate metal(salen) complexes, the structures and structural dynamics of five-coordinate metal (salen) complexes have not previously been analysed in detail. This is crucial information needed to facilitate the design of highly active catalysts based on five-coordinate complexes. Therefore, in this paper we analyse the solid and solution state structures of bimetallic aluminium(salen) complex $\mathbf{1}$ and related complexes and show that the complexes possess 
dynamic structures, interconverting between square-based pyramidal and trigonal bipyramidal geometries. The ability of the complexes to catalyse the synthesis of styrene carbonate from styrene oxide and carbon dioxide is also compared.

\section{Results and discussion}

Solid state structural analysis

In 2010, we reported the single-crystal X-ray structure of complex 1 (Fig. 5a). ${ }^{19}$ That sample was prepared by treatment of the corresponding salen ligand $\left({ }^{t} \mathrm{Bu}\right.$-salen $\left.\mathrm{H}_{2}\right)$ with aluminium triethoxide followed by aqueous work-up (Scheme 2). Both aluminium atoms within the structure were five-coordinate and the structure had an almost linear $\mathrm{Al}-\mathrm{O}-\mathrm{Al}$ unit (bond angle $175.52(15)^{\circ}$ and $170.47(15)^{\circ}$ for the two crystallographically unique molecules in the unit cell). Recently, we attempted to prepare complex $\mathbf{1}$ by treatment of ${ }^{t} \mathrm{Bu}$-salen $\mathrm{H}_{2}$ with diethylaluminium chloride followed by hydrolysis of the intermediate aluminium chloride complex (Scheme 2) and obtained the hydrochloride salt of complex 1.
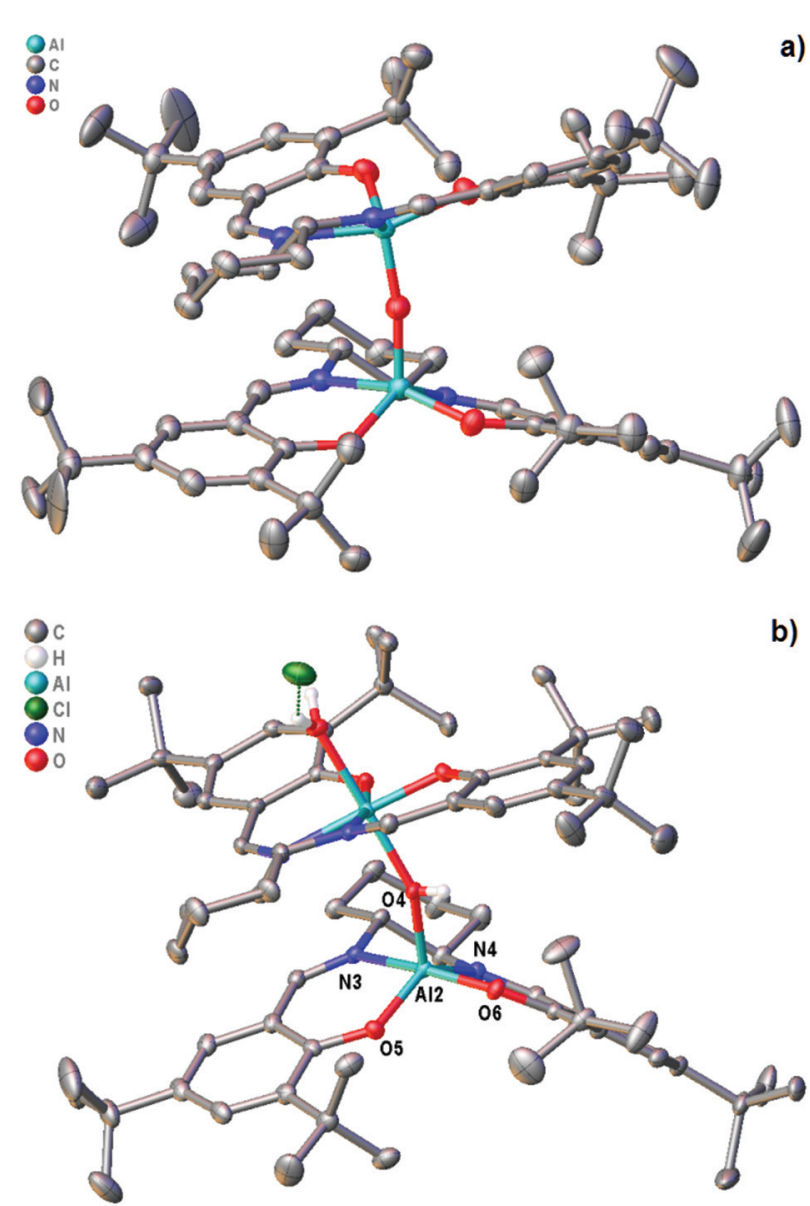

Fig. 5 (a) structure of complex $1^{19}$ (b) structure of complex $1 \cdot \mathrm{HCl}$.

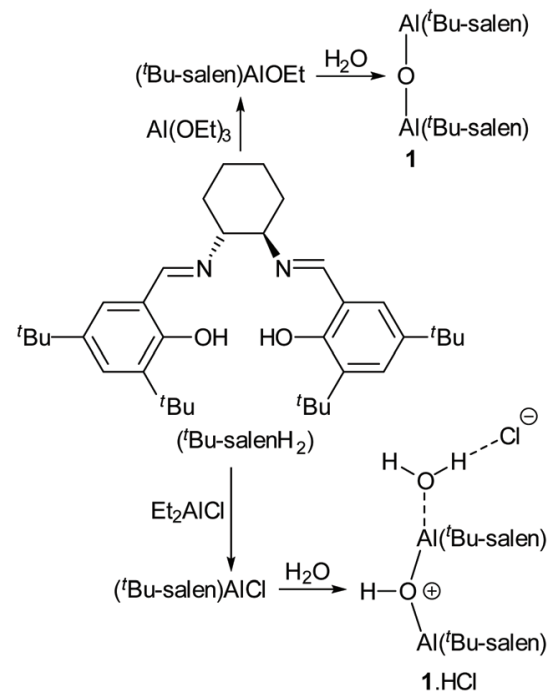

Scheme 2 Synthesis of complexes 1 and $1 \cdot \mathrm{HCl}$.

The single-crystal X-ray structure $\ddagger$ of $\mathbf{1} \cdot \mathbf{H C l}$ (Fig. 5b and ESI $\dagger$ ) showed major differences compared to that of unprotonated 1. The additional proton is localised on the bridging oxygen, resulting in the $\mathrm{Al}-\mathrm{O}-\mathrm{Al}$ bond angle reducing to 153.17 $(11)^{\circ}$. One aluminium atom is six-coordinate (with a water occupying the sixth coordination site hydrogen-bonded to the chloride anion) whilst the other aluminium atom remains fivecoordinate. There is also a marked lengthening in the aluminium to bridging oxygen distances. In complex 1 these are $1.6827(6)$ and $1.6842(6)$, whereas for complex $\mathbf{1} \cdot \mathbf{H C l}$ the distances are $1.8112(17)$ to the five-coordinate aluminium and $1.9407(18)$ to the six-coordinate aluminium.

The salen ligand associated with the six-coordinate aluminium atom is pushed into a more equatorial plane relative to that in unprotonated complex $\mathbf{1}$ and this in turn makes the coordination geometry of the salen ligand attached to the fivecoordinate aluminium more trigonal bipyramidal in complex 1.HCl $\left(\tau_{5}=0.63\right)$ than in complex $1\left(\tau_{5}=0.03\right.$ and 0.46 for the two crystallographically unique molecules). ${ }^{20} \mathrm{O} 6$ and N3 form the two apices (N3-Al2-O6 angle 168.39(8) $)^{\circ}$ ) and $\mathrm{O} 4$, O5 and $\mathrm{N} 4$ form the central triangle $\left(\mathrm{O} 4-\mathrm{Al} 2-\mathrm{N} 4\right.$ angle $118.14(8)^{\circ}, \mathrm{O} 4-$ $\mathrm{Al} 2-\mathrm{O} 5$ angle $110.80(8)^{\circ}$ and $\mathrm{N} 4-\mathrm{Al} 2-\mathrm{O} 5$ angle $\left.130.62(9)^{\circ}\right)$. This effectively blocks the potential sixth coordination site associated with this aluminium atom and prevents it from becoming six-coordinate.

The structural features of the X-ray structure of complex $\mathbf{1} \cdot \mathbf{H C l}$ correlate very well with the previously reported results of DFT calculations on the interaction of complexes 2 and 3 (Fig. 4) with carbon dioxide to give adducts 6 and 7 respectively (Fig. 6). ${ }^{11}$ In complexes 6 and 7, the carbon dioxide was found to interact with the $\mu$-oxo-bridging oxygen, giving $\mathrm{Al}-\mathrm{O}-$ $\mathrm{Al}$ bond angles of $138-145^{\circ}$ compared to an $\mathrm{Al}-\mathrm{O}-\mathrm{Al}$ bond angle of $152^{\circ}$ in the X-ray structure of complex $2 .{ }^{21}$ It was also 
<smiles>O=C(O[AlH2])OC(=O)O[AlH2]</smiles>

Fig. 6 Structures of $\mathrm{CO}_{2}$ adducts 6 and 7.

calculated that the aluminium atoms in complex 7 had increased Lewis acidity compared to those in complex 3, and would form a mono-adduct with ethylene oxide. These calculations and associated experimental results allowed us to propose a mechanism by which complexes 1-3 can catalyse the formation of cyclic carbonates from epoxides and carbon dioxide in the absence of a nucleophilic cocatalyst. ${ }^{11}$

\section{Solution state structural analysis}

To investigate the effect of protonation of complex 1 on the solution state structure and catalytic activity of the resulting complexes, the protonation of complex $\mathbf{1}$ by trifluoracetic acid or anhydrous hydrogen chloride was investigated. Treatment of complex 1 with one equivalent of trifluoroacetic acid (to form 1-TFA) resulted in significant broadening of the ${ }^{1} \mathrm{H}$ and ${ }^{13} \mathrm{C}$ NMR spectra recorded at $298 \mathrm{~K}$ along with changes in chemical shifts. Fig. 7 shows the aromatic/imine region of the ${ }^{1} \mathrm{H}$ NMR spectrum (6.6-8.6 ppm) and the full ${ }^{1} \mathrm{H},{ }^{13} \mathrm{C}$ and ${ }^{19} \mathrm{~F}$ spectra are given in the ESI. $\uparrow$ To better understand the structure of 1-TFA and explain the line broadening, a variable temperature ${ }^{1} \mathrm{H}$ NMR study was carried out in deuterated chloroform between 233 and $328 \mathrm{~K}$. Fig. 8 shows the tert-butyl region

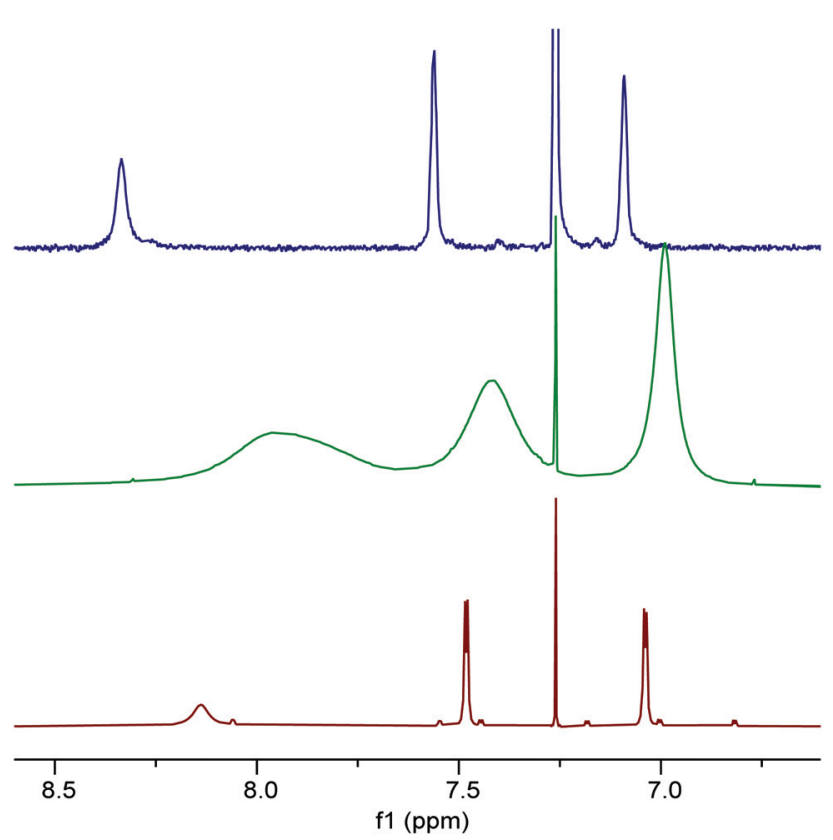

Fig. 7 The aromatic and imine region of the ${ }^{1} \mathrm{H}$ NMR spectra of compounds 1 (red), 1-TFA (green) and 8 (blue) recorded at $400 \mathrm{MHz}$ in $\mathrm{CDCl}_{3}$ at $298 \mathrm{~K}$.

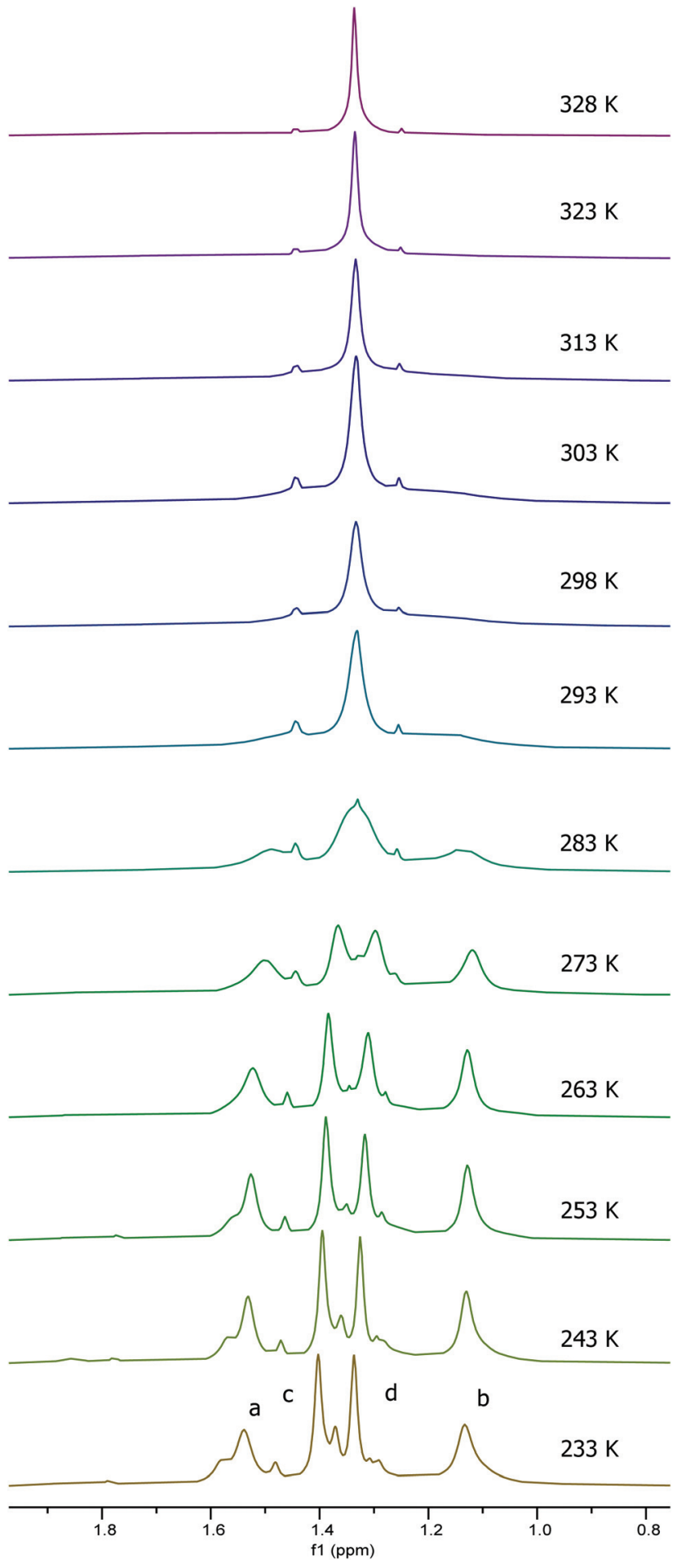

Fig. 8 The tert-butyl group region of the ${ }^{1} \mathrm{H}$ NMR spectra of 1.TFA recorded at $500 \mathrm{MHz}$ in $\mathrm{CDCl}_{3}$ at $233-328 \mathrm{~K}$.

of the resulting spectra and the full spectra are given in the ESI. $\dagger$ At temperatures of $273 \mathrm{~K}$ and below, the ${ }^{1} \mathrm{H}$ NMR spectra of 1.TFA show four separate tert-butyl signals (labelled a-d in Fig. 8) as would be expected for a complex in which both ${ }^{t} \mathrm{Bu}-$ salen units were in the same, non- $C_{2}$-symmetric, environment. 
At $283 \mathrm{~K}$ however, the two central tert-butyl signals (c and d) merge to give a single peak and at $293 \mathrm{~K}$ the two outer signals (a and b) also merge to give an initially very broad peak centred at the same chemical shift as the merged peak derived from signals c and d. As the temperature increases from 293 to $328 \mathrm{~K}$, both merged peaks sharpen and the spectrum exhibits a single peak corresponding to all four tert-butyl groups present on the salen ligand.

The temperature dependent changes in the tert-butyl region of the NMR spectra of 1.TFA are mirrored in the signals present in other regions of the spectra. Thus, the four aromatic and two imine signals present at temperatures below $273 \mathrm{~K}$ merge into two aromatic signals and one imine signal at temperatures of $303 \mathrm{~K}$ and above. The spectra also show a highly temperature dependent $\mathrm{OH}$ signal which appears at $5.7 \mathrm{ppm}$ at $233 \mathrm{~K}$, shifting and broadening to $4.1 \mathrm{ppm}$ at $303 \mathrm{~K}$ before becoming too broad to detect at higher temperatures.

Line shape analysis $\S$ of the tert-butyl signals in the variable temperature NMR spectra of 1.TFA was carried out to allow the rate constant of the exchange process and the Gibbs energies of activation $\left(\Delta G^{\ddagger}\right)$ to be determined at each temperature (see ESI $\dagger$ ). The two sets of tert-butyl signals (a, b and c, d) were modelled separately as non-coupled two spin systems and gave mutually consistent data. The rate constants for the exchange process were found to increase from $0.5-1.5 \mathrm{~s}^{-1}$ at $233 \mathrm{~K}$ to 4300-9000 $\mathrm{s}^{-1}$ at $328 \mathrm{~K}$, but the corresponding Gibbs energies of activation were temperature independent with a value of $56.9 \pm 1.3 \mathrm{~kJ} \mathrm{~mol}^{-1}$ at all twelve temperatures and for both sets of data. Eyring plots of $\ln (k / T)$ against $1 / T$ (Fig. 9) were linear for both data sets and allowed the enthalpy $\left(\Delta H^{\ddagger}\right)$ and entropy $\left(\Delta S^{\ddagger}\right)$ of activation to be determined as $59.0 \pm 3.2 \mathrm{~kJ} \mathrm{~mol}^{-1}$ and $0.0 \pm 0.1 \mathrm{~J} \mathrm{~mol}^{-1} \mathrm{~K}^{-1}$ respectively. The zero value for $\Delta S^{*}$ is consistent with the lack of temperature dependency of $\Delta G^{\ddagger}$ and

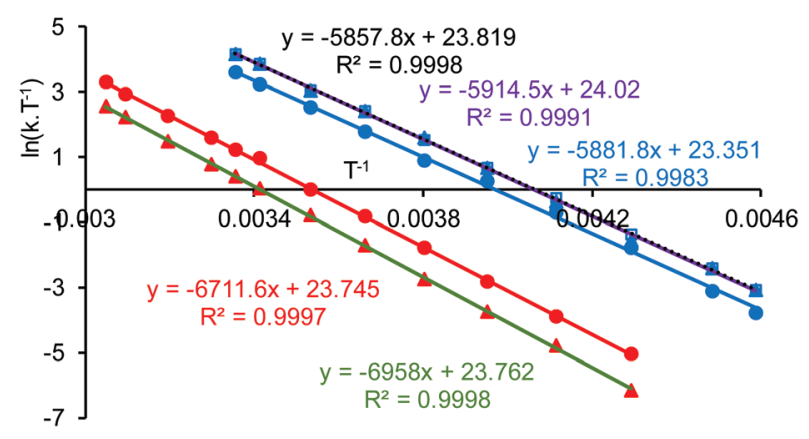

Fig. 9 Eyring plots based on simulations of the variable temperature NMR data for compounds 1.TFA (red points) and 8 (blue points). The two data sets for 1.TFA (red and green trend lines) correspond to analysis of the two separate pairs of tert-butyl signals. The three data sets for $\mathbf{8}$ (blue, purple and black trend lines) correspond to analysis of the two separate pairs of aromatic signals and the pair of imine signals.

$\S$ Line shape analysis was carried out using WinDNMR (https://www.chem.wisc. edu/areas/reich/plt/windnmr.htm). indicates that the process which causes the signals of the tertbutyl groups within 1.TFA to exchange position occurs without a significant change in entropy and so is likely to be an intramolecular rearrangement.

Addition of two equivalents of trifluoroacetic acid to complex 1 resulted in a resharpening of the ${ }^{1} \mathrm{H}$ NMR peaks to positions that differed from those of compound 1 (Fig. 7). The structure of the species formed on treatment of compound 1 with two equivalents of trifluoroacetic acid was shown to be $\begin{array}{llll}\text { mononuclear aluminium }\left({ }^{t} \mathrm{Bu} \text {-salen }\right) \text { trifluoroacetate } & \mathbf{8}\end{array}$ (Scheme 3) by high resolution field desorption mass spectrometry. However, the room temperature ${ }^{1} \mathrm{H}$ NMR spectrum of complex 8 suggested a $C_{2}$-symmetric structure. Therefore, a VT NMR study of complex $\mathbf{8}$ was carried out in deuterated chloroform between 218 and $328 \mathrm{~K}$ (see ESI†). At the lowest temperatures, the imine, aromatic and tert-butyl signals all resolved into two separate peaks; confirming that the complex actually had $C_{1}$-symmetry. For compound $\mathbf{8}$, line shape analysis $\S$ of the imine and aromatic signals in the variable temperature NMR spectra was carried out (see ESI $\dagger$ ) as these underwent more changes than the tert-butyl signals. The imine signals and aromatic hydrogens ortho- and para-to the imine were modelled separately to give three sets of data, all of which were mutually consistent. The Gibbs energies of activation were again temperature independent with a value of $49.0 \pm 1.0 \mathrm{~kJ}$ $\mathrm{mol}^{-1}$ for all 30 data points. Eyring plots of $\ln (k / T)$ against $1 / T$ (Fig. 9) were linear and allowed the enthalpy $\left(\Delta H^{\ddagger}\right)$ and entropy $\left(\Delta S^{\ddagger}\right)$ of activation to be determined as $48.9 \pm 0.3 \mathrm{~kJ} \mathrm{~mol}^{-1}$ and $-0.2 \pm 3.2 \mathrm{~J} \mathrm{~mol}^{-1} \mathrm{~K}^{-1}$ respectively. The approximately zero value for $\Delta S^{\ddagger}$ again indicates that the process which causes the aromatic and imine signals within 8 to exchange position is likely to be an intramolecular rearrangement. The chemistry occurring on treatment of complex 1 with trifluoroacetic acid is therefore summarised in Scheme 3.

The exchange process which results in complexes 1-TFA and 8 appearing to be $C_{2}$-symmetrical at higher temperatures can be explained by the process shown in Scheme 4 . Borrowing terminology used in octahedral, six-coordinate complexes, ${ }^{7}$ a square pyramidal complex I has a salen ligand in the trans-configuration and a vacant coordinate site opposite the $\mathrm{X}$-ligand. Movement of one of the salen ligand's oxygen atoms into this vacant site generates trigonal bipyramidal complex II. The X-ray structures of complexes $\mathbf{1}$ and $\mathbf{1} \cdot \mathbf{H C l}$ provide good evidence for the existence of both of these coordination geometries. Subsequent migration of the $\mathrm{X}$ ligand to the free coordination site within complex II generates a new square pyramidal complex in which the salen ligand has a cis- $\beta$ con-

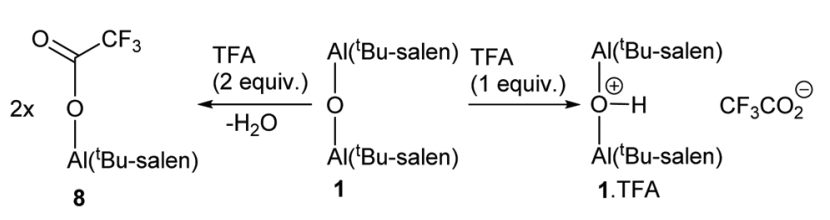

Scheme 3 Synthesis of complexes 1-TFA and 8. 


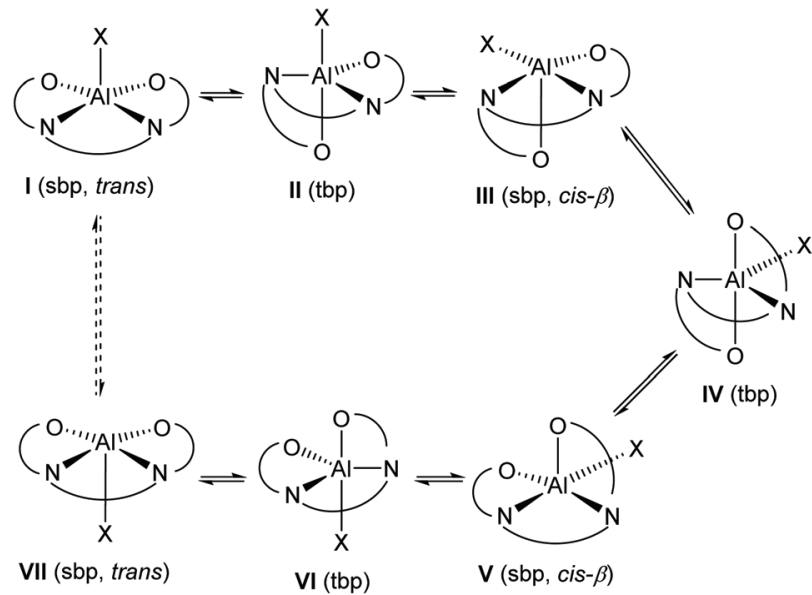

Scheme 4 Salen ligand rearrangement within five-coordinate aluminium(salen) complexes; $\mathrm{sbp}=$ square based pyramid, tbp = trigonal bipyramid; trans and cis- $\beta$ refer to the configuration of the salen ligand within square based pyramidal complexes.

figuration. There are many examples of octahedral metal (salen) complexes with a salen ligand in the cis- $\beta$ configuration. ${ }^{8}$ Movement of the remaining equatorial oxygen atom of the salen ligand into the vacant apical coordination site of complex III generates a new trigonal bipyramidal complex IV. Subsequent migration of the other apically coordinated oxygen of the salen ligand to an equatorial position generates square based pyramidal complex $\mathbf{V}$ in which the salen ligand again has a cis- $\beta$ configuration, but with a different oxygen atom in the apical position compared to complex III. Migration of the $\mathrm{X}$ ligand into the free apical coordination site of complex $\mathbf{V}$ generates trigonal bipyramidal complex VI and finally migration of the remaining apically coordinated oxygen of the salen ligand in complex VI to an equatorial position generates square based pyramidal complex VII with a trans-configuration of the salen ligand. In complex VII, the X ligand is coordinated to the opposite face of the square planar aluminium(salen) unit compared to complex I, so that a time-averaged structure would appear to be $C_{2}$-symmetric.

The pathway shown in Scheme 4 is fully consistent with the activation parameters determined by line-shape analysis of the variable temperature NMR data. No ligand dissociation or association occurs, so the entropy of activation would be expected to be close to zero. The $\mathrm{X}$ group in compound $\mathbf{8}$ is a trifluoroacetyl group, whilst for 1.TFA the $\mathrm{X}$ group is a much larger $\mathrm{OAl}($ salen) unit. The rearrangement shown in Scheme 4 involves the $\mathrm{X}$ group moving into the equatorial plane of square based pyramidal complexes III and $\mathbf{V}$ where steric interactions with the salen ligand will be greater than for structures I and VII where the X group is in the apical position of a square based pyramid. This accounts for the higher values of the enthalpy and Gibbs energy of activation associated with the rearrangement of complex 1.TFA compared to complex 8 .

Close examination of the ${ }^{1} \mathrm{H}$ NMR spectrum of compound 1 (Fig. 7 and ESI $\dagger$ ) showed that in addition to the major, appar- ently $\mathrm{C}_{2}$-symmetrical, species, a second, lower intensity set of signals corresponding to a $C_{1}$-symmetrical complex were present. This is apparent in Fig. 7, where in addition to the three major aromatic/imine peaks, six other signals are present. In this case, all peaks are sharp and well resolved suggesting that at room temperature they exchange only very slowly if at all. A variable temperature NMR study (298-328 K in deuterated chloroform) revealed that the spectra of both the major and minor species were temperature dependent. In this case, although the peaks did undergo changes in chemical shift, they did not coalesce in the accessible temperature range. However, the relative amount of the minor species increased from $9 \%$ at $298 \mathrm{~K}$ to $14 \%$ at $328 \mathrm{~K}$. Thus, the minor peaks present in the ${ }^{1} \mathrm{H}$ NMR spectrum are consistent with complex 1 in which one of the salen ligands is in a trigonal bipyramidal geometry as observed for one of the two independent molecules in the crystal structure of complex $1 .^{19}$ This interpretation was supported by a DOSY experiment (in $\mathrm{CDCl}_{3}$ ) which showed that the major and minor species had very similar diffusion coefficients of $5.4 \times 10^{-10} \mathrm{~m}^{2} \mathrm{~s}^{-1}$ and $5.1 \times$ $10^{-10} \mathrm{~m}^{2} \mathrm{~s}^{-1}$ respectively (see ESI $\dagger$ ). These compare with a value of $2.0 \times 10^{-9} \mathrm{~m}^{2} \mathrm{~s}^{-1}$ for the chloroform present in the NMR solvent.

Protonation of complex 1 using a solution of anhydrous hydrogen chloride in dioxane gave more complex results as the dioxane acted as a Lewis base. Addition of one equivalent of hydrogen chloride to complex $\mathbf{1}$, followed by evaporation of the excess dioxane in vacuo cleanly gave complex 9 (Scheme 5). The ${ }^{1} \mathrm{H}$ NMR spectrum of complex 9 (at room temperature) suggested that the complex was $C_{2}$-symmetric, but the broadness of the signals again indicated that this was due to a dynamic process (Fig. 10 and ESI†). The residual dioxane signal integrated to eight protons, indicating that just one

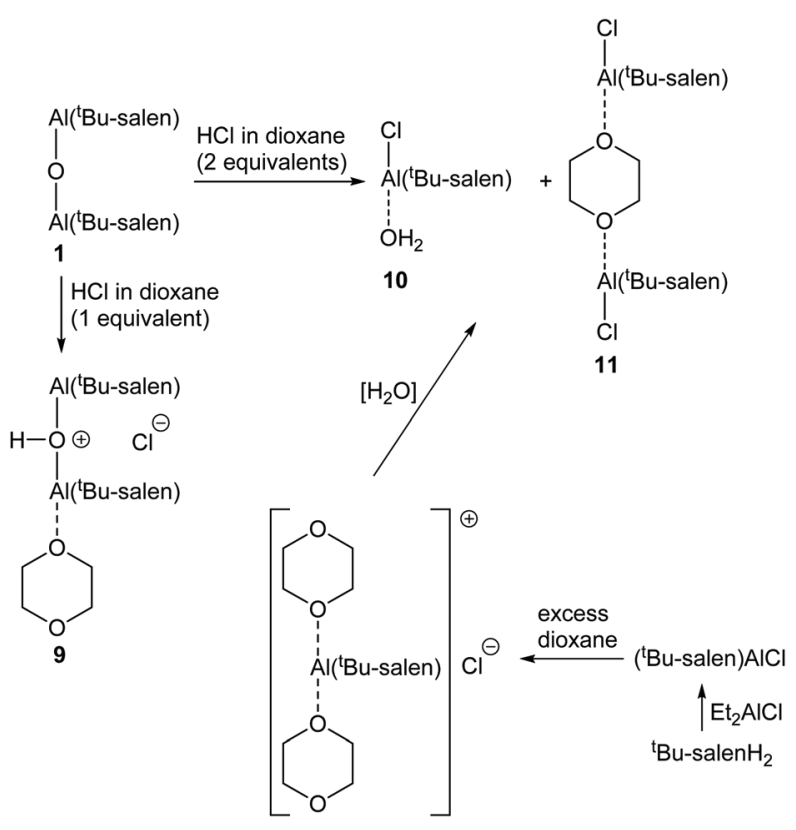

Scheme 5 Synthesis of complexes 9-11. 


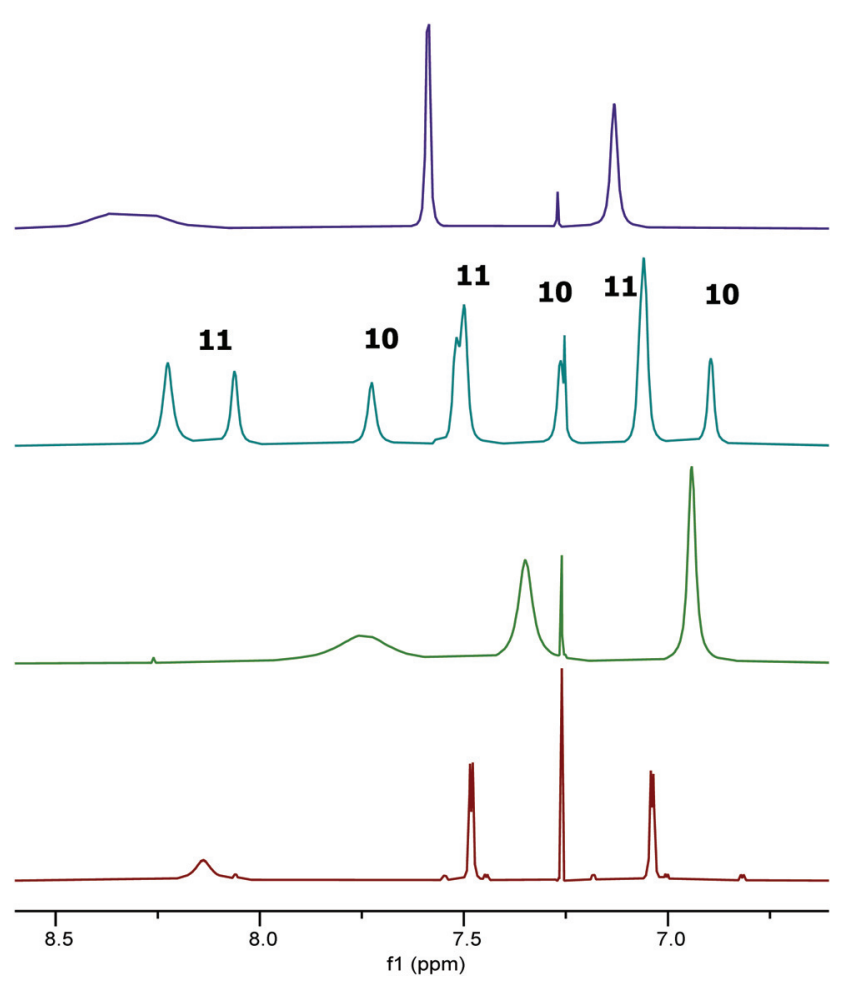

Fig. 10 Extracts of the ${ }^{1} \mathrm{H}$ NMR spectra of compounds: 1 (red); 9 (green); $1: 1.25$ mixture of 10 and 11 (cyan); and 11 (purple) in $\mathrm{CDCl}_{3}$.

dioxane was coordinated within complex 9. The structure of complex $\mathbf{9}$ exactly mirrors the structure of $\mathbf{1} \cdot \mathbf{H C l}$ determined by $\mathrm{X}$-ray crystallography (Fig. 5b) with the water molecule replaced by a dioxane ligand.

In contrast to the treatment of complex 1 with two equivalents of trifluoroacetic acid, addition of two equivalents of hydrogen chloride in dioxane to complex $\mathbf{1}$, followed by removal of excess dioxane in vacuo resulted in the formation of two new species $\mathbf{1 0}$ and $\mathbf{1 1}$ in a $1: 1.25$ ratio (Fig. 10). In addition to the imine and aromatic signals shown in Fig. 10, the full ${ }^{1} \mathrm{H}$ NMR spectrum (see ESI $\dagger$ ) showed a broad $\mathrm{OH}$ peak at $4.8 \mathrm{ppm}$; evidence for coordinated dioxane in complex 11; and the expected cyclohexyl and tert-butyl protons.

To confirm the structures of complexes $\mathbf{1 0}$ and 11, an alternative synthesis of these species was undertaken. Thus, treatment of the ${ }^{t} \mathrm{Bu}$-salen $\mathrm{H}_{2}$ ligand with diethylaluminium chloride gave the known $^{12}$ five-coordinate $\mathrm{Al}\left({ }^{t} \mathrm{Bu}\right.$-salen $) \mathrm{Cl}$ complex (Scheme 5). Addition of excess dioxane to a sample of $\mathrm{Al}\left({ }^{t} \mathrm{Bu}-\right.$ salen $) \mathrm{Cl}$ formed the dioxane solvate $\left\{\left[\mathrm{Al}\left({ }^{t} \mathrm{Bu}-\right.\right.\right.$ salen $)$ (dioxane) $\left.\left.)_{2}\right]^{+} \mathrm{Cl}^{-}\right\}$in situ. The ${ }^{1} \mathrm{H}$ NMR spectra of this solvate did not match those of complexes 10 and/or 11 (see ESI $\dagger$ ). However, after evaporation of excess dioxane from the solvate, the ${ }^{1} \mathrm{H}$ NMR spectrum did match that of complexes 10 and 11 obtained from complex 1 , though with a $1: 2.5$ ratio of $10: 11$ (see $\mathrm{ESI}^{\dagger}$ ).

Treatment of bimetallic complex 1 with anhydrous hydrogen chloride to give products in which the $\mu$-oxo bridge has been broken will produce half an equivalent of water relative to the concentration of aluminium. Therefore, a $1: 1$ ratio of complexes 10 and 11 would be expected to form when complex 1 was treated with two equivalents of anhydrous hydrogen chloride and the observed ratio was $1: 1.25$. In contrast, no water is generated when $\mathrm{Al}\left({ }^{t} \mathrm{Bu}\right.$-salen $) \mathrm{Cl}$ is treated with dioxane. Hence, the formation of complex 10 under these conditions must be due to adventitious water in the reaction and this accounts for the lower amount of complex $\mathbf{1 0}$ formed by this route. By carrying out the synthesis from $\mathrm{Al}\left({ }^{t} \mathrm{Bu}\right.$-salen $) \mathrm{Cl}$ under rigorously anhydrous conditions with evaporation of excess dioxane on a Schlenk line, the formation of complex 10 could be completely avoided and only complex 11 was formed (Fig. 10 and ESI $\dagger$ ). The ${ }^{1} \mathrm{H}$ NMR spectrum of pure complex 11 confirmed that half a dioxane molecule was present for each $\mathrm{Al}\left({ }^{t} \mathrm{Bu}\right.$-salen $)$ unit.

As shown in Fig. 10, the ${ }^{1} \mathrm{H}$ NMR signals for complex 11 in the mixture of species $\mathbf{1 0}$ and $\mathbf{1 1}$ do not exactly superimpose with the signals observed when only species $\mathbf{1 1}$ was present. However, a NOESY spectrum recorded on a sample with a 1:2.5 ratio of complexes $\mathbf{1 0}$ and $\mathbf{1 1}$ showed cross-peaks between the signals for each species, indicating that they were in chemical exchange with each other (see ESI $\dagger$ ). Thus, slightly different chemical shifts and line widths would be expected for complex $\mathbf{1 1}$ in the presence and absence of complex $\mathbf{1 0 .}$

It was apparent from the room temperature ${ }^{1} \mathrm{H}$ NMR spectra of compounds $\mathbf{1 0}$ and $\mathbf{1 1}$ that aspects of their structures were again not fully explained by the spectra. In particular, the aromatic signals shown in Fig. 10 were far simpler than would be expected and the imine signals in Fig. 10 appeared extremely broad or to be split into two separate peaks. Therefore a variable temperature ${ }^{1} \mathrm{H}$ NMR study was undertaken on the $1: 2.5$ mixture of 10 and 11 in deuterated chloroform at $500 \mathrm{MHz}$ between 218 and $328 \mathrm{~K}$. Fig. 11 shows the tert-butyl region of the resulting spectra and the full spectra are given in the ESI. $\dagger$ At $218 \mathrm{~K}$, eight tert-butyl signals (labelled $\mathrm{a}-\mathrm{h}$ ) are present between 1.55 and $0.95 \mathrm{ppm}$. This is the number expected for a combination of complexes $\mathbf{1 0}$ and 11 as within each of these complexes the aluminium $\left({ }^{t} \mathrm{Bu}-\right.$ salen) units are not $C_{2}$-symmetric. However, as the temperature increases, the tert-butyl signals start to merge, first to six signals at $243-253 \mathrm{~K}$, then to two signals (one of which is very broad) at $313 \mathrm{~K}$. Similar changes are apparent in other regions of the spectra (see ESI†). The signal for the coordinated water molecule of complex 10 undergoes a particularly large change in chemical shift: from $5.75 \mathrm{ppm}$ at $218 \mathrm{~K}$ to $3.20 \mathrm{ppm}$ at $328 \mathrm{~K}$.

The eight tert-butyl signals could be divided into two groups of four ( $a-d$ and $e-h$ ) each of which merges to a single peak at the higher temperatures and which correspond to the tert-butyl groups ortho- and para-to the phenols in the salen ligand. These two sets of tert-butyl signals were separately subjected to line shape analysis§ (using a four non-coupled spin model, see ESI $\dagger$ ) to allow rate constants and Gibbs energies of activation to be determined at each temperature. For this system, $\Delta G^{*}$ was temperature dependent, increasing steadily from $50.7 \mathrm{~kJ} \mathrm{~mol}^{-1}$ at $218 \mathrm{~K}$ to $67.6 \mathrm{~kJ} \mathrm{~mol}^{-1}$ at $328 \mathrm{~K}$ based on 


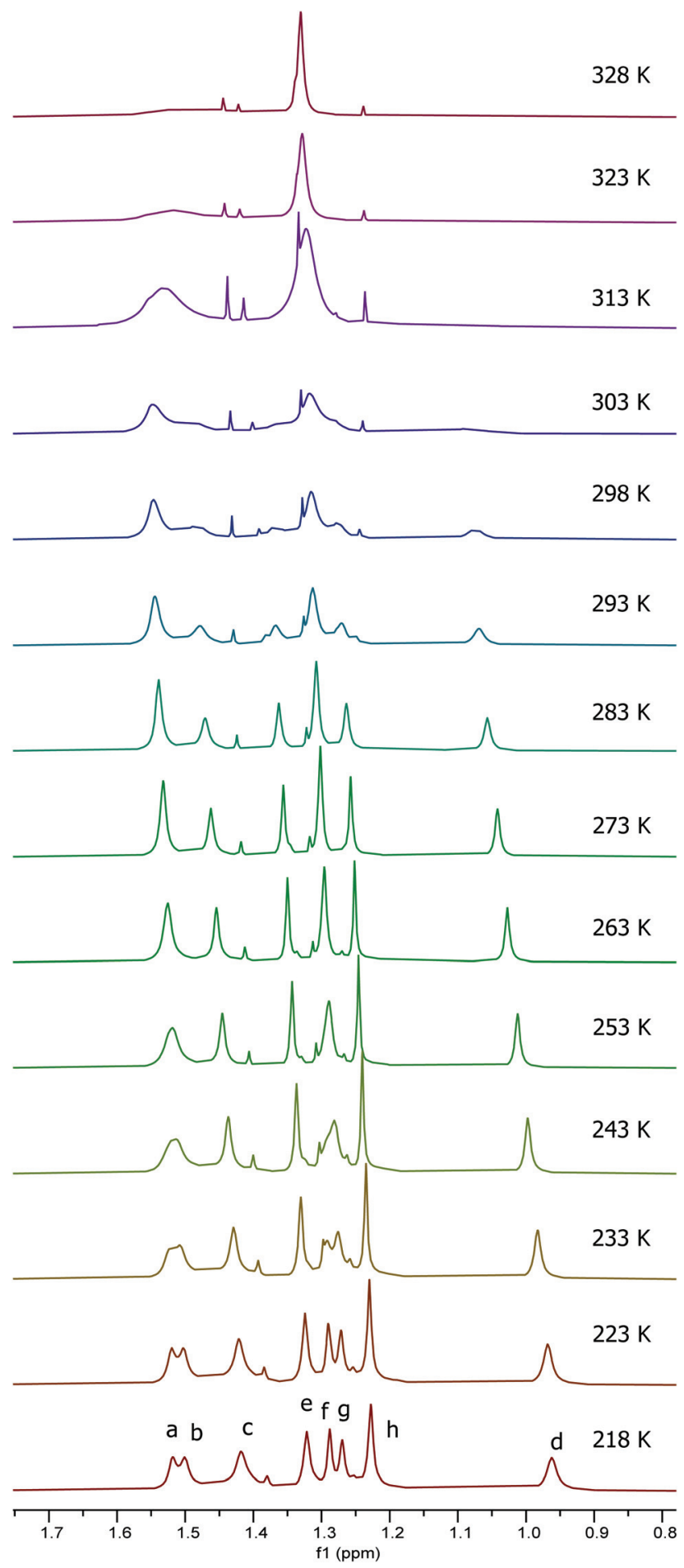

Fig. 11 Stacked plot of extracts of the $500 \mathrm{MHz}^{1} \mathrm{H}$ NMR spectra of a $1: 2.5$ mixture of compounds 10 and 11 in $\mathrm{CDCl}_{3}$ recorded at 218 to $328 \mathrm{~K}$.

analysis of signals a-d and from $52.8 \mathrm{~kJ} \mathrm{~mol}^{-1}$ at $218 \mathrm{~K}$ to $69.5 \mathrm{~kJ} \mathrm{~mol}^{-1}$ at $328 \mathrm{~K}$ based on analysis of signals e-f. Eyring plots for the two sets of data are given in Fig. 12 and allowed $\Delta H^{\ddagger}$ to be calculated as $17.9 \pm 1.1 \mathrm{~kJ} \mathrm{~mol}^{-1}$ and $\Delta S^{\ddagger}$ to be determined as $-155 \pm 1 \mathrm{~J} \mathrm{~mol}^{-1} \mathrm{~K}^{-1}$.

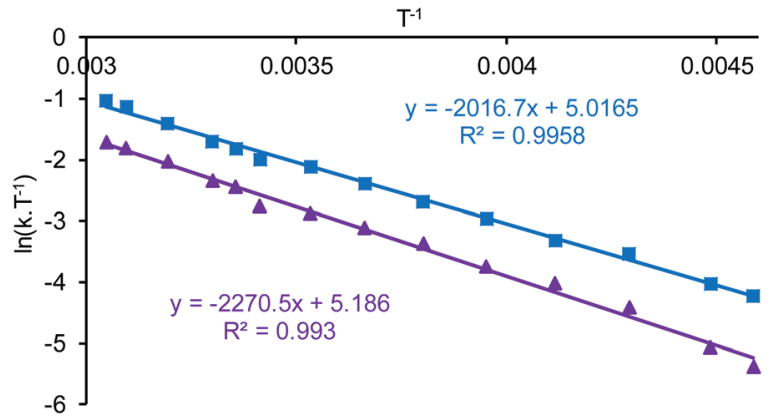

Fig. 12 Eyring plots based on the simulations of the variable temperature NMR data a 1:2.5 mixture of compounds 10 and 11 . The blue points and line correspond to analysis of peaks $a-d$ whilst the purple points and line correspond to analysis of peaks $\mathrm{e}-\mathrm{h}$.

Within the mixture of compounds 10 and 11, three separate exchange processes will occur. Both compounds can independently undergo the same salen ligand rearrangement discussed above for compounds 1.TFA and 8 and illustrated in Scheme 4. This intramolecular rearrangement does however, require the initial dissociation of a weakly bound water or dioxane ligand to generate a five-coordinate complex and hence will have a positive entropy of activation. Compounds $\mathbf{1 0}$ and $\mathbf{1 1}$ also exchange their weakly bound water and dioxane ligands as illustrated in Scheme 6 and the negative value observed for $\Delta S^{\ddagger}$ suggests that this occurs through an associative mechanism such as that shown in the transition state structure in Scheme 6. The associative ligand exchange outweighs the dissociative ligand rearrangement, resulting in an overall negative entropy of activation.

\section{Investigation of the lewis basicity of aluminium(salen) complexes}

Since water and dioxane were capable of acting as Lewis bases towards the $\mathrm{Al}\left({ }^{t} \mathrm{Bu}-\mathrm{salen}\right)$ units in complexes $\mathbf{1 0}$ and $\mathbf{1 1}$, the

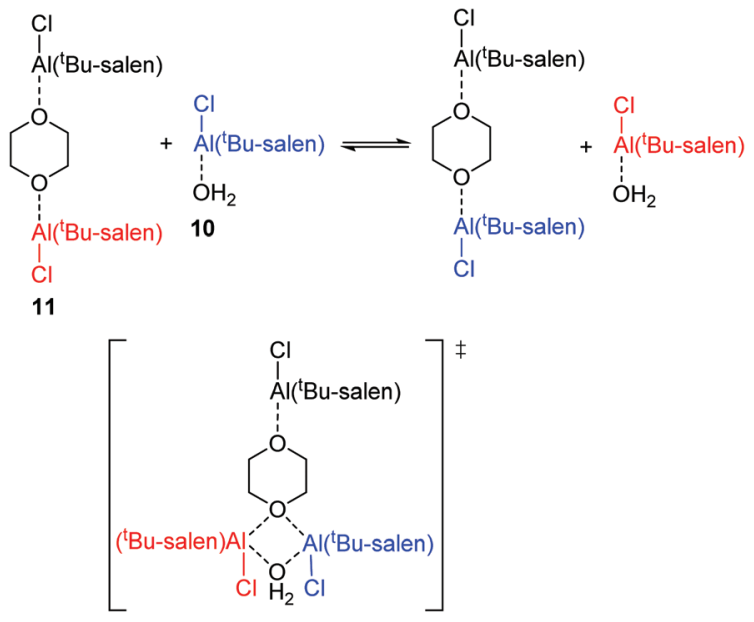

Scheme 6 Associative mechanism for the exchange of neutral ligands between compounds 10 and 11 . 
ability of an epoxide to coordinate to complexes 1, 1·TFA, 9 and ( $\left.{ }^{t} \mathrm{Bu}-\mathrm{salen}\right) \mathrm{AlCl}$ was investigated to probe the significance of these results to the mechanisms of reactions catalysed by these and related complexes (Scheme 1). DFT calculations ${ }^{11}$ have previously shown that the Lewis acidity of complex $\mathbf{1}$ could be increased by withdrawing some of the electron density associated with the bridging oxygen. 1,2-Epoxyhexane was chosen as the Lewis base on the basis of its convenient boiling point (118-120 $\left.{ }^{\circ} \mathrm{C}\right)$. Addition of excess 1,2-epoxyhexane to a solution of complex $\mathbf{1}$ in deuterated chloroform resulted in detectable shifts in the ${ }^{1} \mathrm{H}$ NMR signals of both the aromatic hydrogens of complex 1 and the hydrogens of 1,2-epoxyhexane (see ESI $\dagger$ ). Evaporation of the 1,2-epoxyhexane resulted in the aromatic hydrogen signals of complex $\mathbf{1}$ returning to their original chemical shifts. This indicates that complex 1 can act as a Lewis acid towards epoxides as required by its proposed mechanism of action in the presence of tetrabutylammonium bromide as a cocatalyst, but that the epoxide is only weakly bound to the aluminium complex. ${ }^{9}$

Addition of excess 1,2-epoxyhexane to a solution of $\left({ }^{t} \mathrm{Bu}\right.$ salen)AlCl in deuterated chloroform resulted in smaller shifts to the ${ }^{1} \mathrm{H}$ NMR aromatic and epoxide signals (see ESI $\dagger$ ). These were accompanied by the appearance of multiple new signals in the range of 3-4 ppm and 6.5-9 ppm, indicative of the epoxide having undergone ring-opening to form diol and oligomeric ethers which compete with the 1,2-epoxyhexane for coordination to the aluminium. Consistent with this, when the excess 1,2-epoxyhexane was evaporated, the aromatic signals did not revert to their original shifts and the multiple peaks at 3-4 ppm were still present in the ${ }^{1} \mathrm{H}$ NMR spectrum. There is literature precedent for aluminium(salen) complexes initiating the ring-opening polymerisation of epoxides. ${ }^{22}$

When excess 1,2-epoxyhexane was added to 1-TFA, no changes in the ${ }^{1} \mathrm{H}$ NMR chemical shifts of the aromatic or epoxide hydrogens was observed, though the aromatic and imine signals did become sharper (see ESI $\dagger$ ). On evaporation of excess 1,2-epoxyhexane, changes in the aromatic and imine signals did become apparent. In addition to the three signals at the original positions, new signals corresponding to a salen ligand in a non- $C_{2}$ symmetric environment appeared as did peaks between 3 and $4 \mathrm{ppm}$ in the ${ }^{1} \mathrm{H}$ NMR spectrum and between 65 and $75 \mathrm{ppm}$ in the ${ }^{13} \mathrm{C}$ NMR spectrum corresponding to ring-opened epoxide. These results can be explained on the basis that 1,2-epoxyhexane undergoes ringopening as the solution is being evaporated to give oligomeric ethers $^{22}$ which coordinate to one of the aluminium centres of 1.TFA, forming a six-coordinated aluminium which can no longer undergo the salen ligand rearrangement shown in Scheme 4. A very similar situation was observed when 1,2-epoxyhexane was added to complex $\mathbf{9}$, though in this case a small change in the chemical shift of the epoxide signals was seen (see $\mathrm{ESI}_{\dagger}$ ). On evaporation of the 1,2-epoxyhexane, the dioxane initially weakly coordinated to complex 9 was also removed. These results indicate that complexes 1, 1.TFA, 9 and $\left({ }^{t} \mathrm{Bu}-\right.$ salen)AlCl are all capable of acting as Lewis acids towards 1,2epoxyhexane and in the case of 1-TFA, 9 and ( ${ }^{t} \mathrm{Bu}$-salen) $\mathrm{AlCl}$ this activation of the epoxide results in its ring-opening by a nucleophile present in the reaction to give oligomers ${ }^{22}$ which also coordinate to the aluminium(salen) units.

\section{Catalytic activity of aluminium(salen) complexes}

Given their abilities to coordinate epoxides, the relative abilities of complexes 1, 1.TFA, 8 and 9 to catalyse the synthesis of styrene carbonate $\mathbf{1 3}$ from styrene oxide $\mathbf{1 2}$ and carbon dioxide under two different sets of solvent-free reaction conditions were investigated. Initially, reactions were carried out at $25{ }^{\circ} \mathrm{C}$ and 1 bar pressure of carbon dioxide, using a combination of aluminium complex and tetrabutylammonium bromide as catalyst $^{9,19}$ (Scheme 7, conditions A) and the results are detailed in Table 1. Entries 1-3 confirm that at $25{ }^{\circ} \mathrm{C}$ and one bar carbon dioxide pressure, neither complex 1 nor tetrabutylammonium bromide is an effective catalyst, but when used together they form an effective synergistic catalyst system. Entry 4 shows that this catalytic activity is maintained in the presence of dioxane, indicating that the coordinated dioxane present in complex 9 could be displaced by styrene oxide during the catalytic cycle. This is confirmed by entry 5 which shows that bimetallic complex 9 had similar catalytic activity

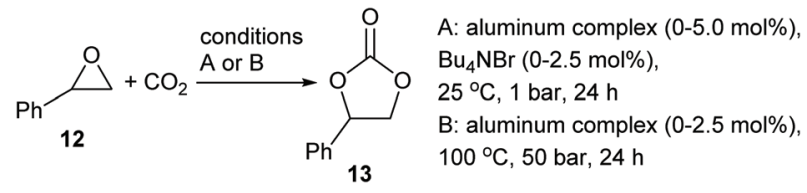

Scheme 7 Synthesis of styrene carbonate 13 from styrene oxide 12 and $\mathrm{CO}_{2}$.

Table 1 Synthesis of styrene carbonate 13 catalysed by complexes 1 , 1.TFA, 8 and 9

\begin{tabular}{|c|c|c|c|c|c|}
\hline Entry & $\begin{array}{l}\text { Aluminium } \\
\text { complex } \\
(\mathrm{mol} \%)\end{array}$ & $\begin{array}{l}\mathrm{Bu}_{4} \mathrm{NBr} \\
(\mathrm{mol} \%)\end{array}$ & $\begin{array}{l}T \\
\left({ }^{\circ} \mathrm{C}\right)\end{array}$ & $\begin{array}{l}P \\
\text { (bar) }\end{array}$ & $\begin{array}{l}\text { Conversion }^{a} \text { or } \\
\text { (isolated yield) }\end{array}$ \\
\hline 1 & None & 2.5 & 25 & 1 & 0 \\
\hline 2 & $1(2.5)$ & 0 & 25 & 1 & 9 \\
\hline 3 & $1(2.5)$ & 2.5 & 25 & 1 & 53 \\
\hline 4 & $1^{b}(2.5)$ & 2.5 & 25 & 1 & 55 \\
\hline 5 & $9(2.5)$ & 2.5 & 25 & 1 & 46 \\
\hline 6 & 1.TFA $(2.5)$ & 2.5 & 25 & 1 & 36 \\
\hline 7 & 1. TFA ${ }^{c}(2.5)$ & 2.5 & 25 & 1 & 48 \\
\hline 8 & $8(2.5)$ & 2.5 & 25 & 1 & 27 \\
\hline 9 & $8^{d}(5.0)$ & 2.5 & 25 & 1 & 11 \\
\hline 10 & None & 0 & 100 & 50 & 0 \\
\hline 11 & $1(2.5)$ & 0 & 100 & 50 & (59) \\
\hline 13 & 1.TFA $(2.5)$ & 0 & 100 & 50 & (29) \\
\hline 12 & $9(2.5)$ & 0 & 100 & 50 & (40) \\
\hline 14 & $8(2.5)$ & 0 & 100 & 50 & (7) \\
\hline
\end{tabular}

${ }^{a}$ Determined by ${ }^{1} \mathrm{H}$ NMR analysis of the reaction mixture. ${ }^{b} 5 \mathrm{~mol} \%$ of dioxane added. ${ }^{c}$ 1.TFA was formed in situ by addition of TFA $(2.5 \mathrm{~mol} \%)$ to complex $1(2.5 \mathrm{~mol} \%)$ prior to addition of $\mathrm{Bu}_{4} \mathrm{NBr}$. ${ }^{d}$ Complex 8 (5 mol\%) was formed in situ by addition of TFA (5.0 mol\%) to complex 1 (2.5 mol\%) prior to addition of $\mathrm{Bu}_{4} \mathrm{NBr}$. 
to complex 1. Entries 6 and 7 show that 1.TFA also has a similar catalytic activity to complex 1 especially when generated in situ. In contrast, entries 8 and 9 show that the monometallic complex 8 has lower catalytic activity than complex $\mathbf{1}$, whether preformed complex 8 was used at 2.5 mol\% loading or complex 8 was generated in situ at 5 mol\% loading.

The results presented in entries 3-7 of Table 1 suggest that it is the nucleophile (tetrabutylammonium bromide) rather than the Lewis acid that is the dominant factor in determining the effectiveness of a tetrabutylammonium bromide/bimetallic aluminium(salen) complex catalyst system. Therefore, 1, 1.TFA, $\mathbf{8}$ and $\mathbf{9}$ were tested as catalysts under alternative, tetrabutylammonium bromide free conditions at $100{ }^{\circ} \mathrm{C}$ and 50 bar carbon dioxide pressure $^{11}$ (Scheme 7, conditions B). Entry 10 shows that under these conditions, no reaction occurs in the absence of a catalyst. Complex 1 shows reasonable catalytic activity under these reaction conditions (entry 11). Protonation of complex 1 with trifluoroactic acid to form 1.TFA or with $\mathrm{HCl}$ to form complex 9 reduced the catalytic activity (entries 12 and 13). The significantly higher catalytic activity of complex 9 compared to 1.TFA can be explained by the presence of a reasonable nucleophile (chloride) in complex 9 but not in complex 1-TFA. In the presence of chloride two catalytic cycles are possible under these reaction conditions, involving epoxide ring-opening by chloride or carboxylate as previously determined. ${ }^{9-11,19}$ The lower catalytic activity of both complexes 9 and 1.TFA compared to complex $\mathbf{1}$ is consistent with the need for the $\mu$-oxo group of the complexes to interact with carbon dioxide (as shown in Fig. 6) during the catalytic cycle in the absence of a nucleophilic cocatalyst. ${ }^{10,11}$ Protonation of the $\mu$-oxo group will inhibit this interaction. Finally, entry 14 shows that monometallic complex $\mathbf{8}$ is again a very poor catalyst under these conditions.

\section{Conclusions}

Five-coordinate aluminium(salen) complexes are shown to have dynamic structures with both trigonal bipyramidal and square based pyramidal conformations accessible in both the solution and solid states. These interconvert by a salen ligand rearrangement mechanism which line shape analysis of variable temperature NMR spectra show is neither associative or dissociative. The rearrangement is often rapid on the NMR timescale at ambient temperature which results in deceptively simple, apparently $C_{2}$-symmetrical structures being observed.

Protonation of $\mu$-oxo bridged bimetallic aluminium(salen) complexes occurs on the bridging oxygen and results in significant changes to the coordination geometry and ligand conformations around the aluminium centres. Protonation also increases the Lewis acidity of the aluminium centres as shown by their interaction by Lewis bases such as water, dioxane and 1,2-epoxyhexane. However, the protonated complexes have lower catalytic activity than the unprotonated complex for the synthesis of styrene carbonate from styrene oxide and carbon dioxide which suggests that nucleophilicity (of a cocatalyst or the $\mu$-oxo bridge) is more important than Lewis acidity for the catalytic activity.

\section{Experimental}

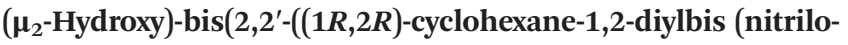
methylylidene)) bis(4,6-di-tert-butylphenolato))-di-aluminium chloride hydrate $\mathbf{1} \cdot \mathbf{H C l}$

2,2'-((1R,2R)-cyclohexane-1,2-diylbis(nitrilomethylylidene))bis (4,6-di-tert-butylphenolato)-aluminium chloride ${ }^{12}$ was dissolved in chloroform and the ensuing solution allowed to slowly evaporate to dryness at room temperature. The resulting solid was dissolved in toluene and the solution allowed to slowly evaporate at room temperature, giving crystals of $\mathbf{1} \cdot \mathbf{H C l}$ suitable for analysis by X-ray crystallography. Diffraction data were collected at $110 \mathrm{~K}$, with $\mathrm{Cu}-\mathrm{K}_{\alpha}$ radiation $(\lambda=1.54184 \AA)$ on an Oxford Diffraction SuperNova using an EOS CCD camera. The crystal was cooled with an Oxford Instruments Cryojet. Diffractometer control, data collection, initial unit cell determination, frame integration and unit-cell refinement was carried out with "Crysalis". ${ }^{23}$ Face-indexed absorption corrections were applied using spherical harmonics, implemented in SCALE3 ABSPACK scaling algorithm. ${ }^{24}$ OLEX2 ${ }^{25}$ was used for overall structure solution, refinement and preparation of computer graphics and publication data. Within OLEX2, the algorithm used for structure solution was "ShelXS direct methods", ${ }^{26}$ using direct methods. Refinement by full-matrix least-squares used the SHELXL algorithm ${ }^{23}$ within OLEX2 ${ }^{22}$ All non-hydrogen atoms were refined anisotropically. Hydrogen atoms were placed using a "riding model" and included in the refinement at calculated positions except for $\mathrm{O}-\mathrm{H}$ hydrogens which were located by difference map. The difference map revealed the presence of three molecules of solvent occupying at least three orientations. All attempts to model this solvent using a discrete atom model failed and so a solvent mask was used to model this electron density.

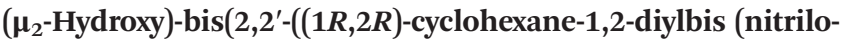 methylylidene))bis(4,6-di-tert-butylphenolato))-di-aluminium trifluoroacetate 1.TFA}

To a stirred solution of complex $1(0.100 \mathrm{~g}, 0.086 \mathrm{mmol})$ in $\mathrm{CH}_{2} \mathrm{Cl}_{2}(0.5 \mathrm{~mL})$ was added trifluoroacetic acid $(6.6 \mu \mathrm{L}, 1$ equiv.). The solution was stirred for 5 minutes then evaporated in vacuo to provide 1.TFA $(0.110 \mathrm{~g}, 0.086 \mathrm{mmol})$ in quantitative yield. $[\alpha]_{\mathrm{D}}^{20}-548$ (c 1.0, $\mathrm{CH}_{2} \mathrm{Cl}_{2}$ ); $\nu_{\max }(\mathrm{ATR}) 3638,2952,2907$, 2866, 1706 and $1622 \mathrm{~cm}^{-1} ; \delta_{\mathrm{H}}(400 \mathrm{MHz}, 298 \mathrm{~K}): 7.92(4 \mathrm{H}, \mathrm{br}$, $4 \times \mathrm{CH}=\mathrm{N}), 7.42(4 \mathrm{H}, \mathrm{br}, 4 \times \mathrm{ArCH}), 6.99(4 \mathrm{H}, \mathrm{br}, 4 \times \mathrm{ArCH})$, $3.25(5 \mathrm{H}, \mathrm{br}, 4 \times \mathrm{NCH}+\mathrm{OH}), 2.32\left(4 \mathrm{H}, \mathrm{br}, 2 \times \mathrm{CH}_{2}\right), 2.0-1.0$ $\left(12 \mathrm{H}, \mathrm{br}, 6 \times \mathrm{CH}_{2}\right), 1.32\left(72 \mathrm{H}, \mathrm{s}, 4 \times \mathrm{C}\left(\mathrm{CH}_{3}\right)_{3}\right) ; \delta_{\mathrm{C}}(100 \mathrm{MHz}$, $298 \mathrm{~K}):$ 167-164 (br), 162.1, 158.4 (q $\left.{ }^{2} J_{\mathrm{CF}} 36.3 \mathrm{~Hz}\right), 140.4$, 139-137 (br), 130.5, 129-127 (br), 118.0, 116.1 (q ${ }^{1} J_{\mathrm{CF}} 292.1$ $\mathrm{Hz}), 65-62$ (br), 35.4, 33.9, 31.4, 29.4, 26.9, 23.3; $\delta_{\mathrm{F}}(377 \mathrm{MHz}$, $298 \mathrm{~K}):-76.2 ; \mathrm{m} / \mathrm{z}\left(\mathrm{FD}^{+}\right)$: found 1158.76872; $\mathrm{C}_{72} \mathrm{H}_{104} \mathrm{~N}_{4} \mathrm{O}_{5} \mathrm{Al}_{2}$ $(\mathrm{M}-\mathrm{TFA})^{+}$requires 1158.76320; found: $\mathrm{C} 69.0, \mathrm{H} \mathrm{8.7,} \mathrm{N} \mathrm{4.5 \% ;}$ $\mathrm{C}_{74} \mathrm{H}_{104} \mathrm{~N}_{4} \mathrm{O}_{7} \mathrm{~F}_{3} \mathrm{Al}_{2} \cdot \mathrm{H}_{2} \mathrm{O}$ requires: C 68.9, $\mathrm{H}$ 8.3, N 4.3\%. 
2,2'-((1R,2R)-Cyclohexane-1,2-diylbis(nitrilomethylylidene))bis (4,6-di-tert-butylphenolato)-aluminium trifluoroacetate 8

To a stirred solution of complex $1(0.100 \mathrm{~g}, 0.086 \mathrm{mmol})$ in $\mathrm{CH}_{2} \mathrm{Cl}_{2}(0.5 \mathrm{~mL})$ was added trifluoroacetic acid $(13.2 \mu \mathrm{L}, 2$ equiv.). The solution was stirred for 5 minutes then evaporated in vacuo to provide complex $8(0.118 \mathrm{~g}, 0.173 \mathrm{mmol})$ in quantitative yield. $[\alpha]_{\mathrm{D}}^{20}-410\left(c 1.0, \mathrm{CH}_{2} \mathrm{Cl}_{2}\right) ; \nu_{\max }(\mathrm{ATR}) 2953,2908$, 2867, 1696 and $1622 \mathrm{~cm}^{-1} ; \delta_{\mathrm{H}}(400 \mathrm{MHz}, 298 \mathrm{~K}): 8.33(2 \mathrm{H}, \mathrm{s}, 2 \times$ $\mathrm{CH}=\mathrm{N}), 7.56\left(2 \mathrm{H}, \mathrm{d}{ }^{4} J_{\mathrm{HH}} 2.1 \mathrm{~Hz}, 2 \times \mathrm{ArCH}\right), 7.09\left(2 \mathrm{H}, \mathrm{d}{ }^{4} J_{\mathrm{HH}}\right.$ $2.2 \mathrm{~Hz}, 2 \times \mathrm{ArCH}), 3.50(2 \mathrm{H}, \mathrm{br}, 2 \times \mathrm{NCH}), 2.54\left(2 \mathrm{H}, \mathrm{br}, \mathrm{CH}_{2}\right)$, $2.10\left(2 \mathrm{H}\right.$, br, $\left.\mathrm{CH}_{2}\right), 1.59\left(2 \mathrm{H}\right.$, br, $\left.\mathrm{CH}_{2}\right), 1.51(18 \mathrm{H}, \mathrm{s}, 2 \times$ $\left.\mathrm{C}\left(\mathrm{CH}_{3}\right)_{3}\right), 1.47\left(2 \mathrm{H}\right.$, br, $\left.\mathrm{CH}_{2}\right), 1.31\left(18 \mathrm{H}, \mathrm{s}, 2 \times \mathrm{C}\left(\mathrm{CH}_{3}\right)_{3}\right)$; $\delta_{\mathrm{C}}(100 \mathrm{MHz}, 298 \mathrm{~K}): 158.4\left(\mathrm{q}^{2} J_{\mathrm{CF}} 38.4 \mathrm{~Hz}\right), 141.1,139.0,136.4$, 131.4, 127.9, 126.2, 118.2, 115.7 (q ${ }^{1} J_{\mathrm{CF}} 287.6 \mathrm{~Hz}$ ), 65-63 (br), 35.6, 34.2, 31.5, 29.7, 27.3, 23.9; $\delta_{\mathrm{F}}(377 \mathrm{MHz}, 298 \mathrm{~K}):-76.2$; $m / z\left(\mathrm{FD}^{+}\right)$: found 684.37197; $\mathrm{C}_{38} \mathrm{H}_{52} \mathrm{~N}_{2} \mathrm{O}_{4} \mathrm{~F}_{3} \mathrm{Al}\left(\mathrm{M}^{+}\right)$requires 684.36891; found: $\mathrm{C} \quad 63.2, \quad \mathrm{H} \quad 7.5, \quad \mathrm{~N} \quad 3.9 \%$; $\mathrm{C}_{38} \mathrm{H}_{52} \mathrm{~N}_{2} \mathrm{O}_{4} \mathrm{~F}_{3} \mathrm{Al} \cdot 2 \mathrm{H}_{2} \mathrm{O}$ requires: C 63.2, $\mathrm{H}$ 7.8, N 3.9\%.

( $\mu_{2}$-Hydroxy)-bis(2,2'-((1R,2R)-cyclohexane-1,2-diylbis (nitrilomethylylidene)) bis(4,6-di-tert-butylphenolato))-di-aluminium chloride dioxane 9

To a stirred solution of complex $1(0.100 \mathrm{~g}, 0.086 \mathrm{mmol})$ in $\mathrm{CH}_{2} \mathrm{Cl}_{2}(0.5 \mathrm{~mL})$ was added a solution of $\mathrm{HCl}$ in dioxane (21.6 $\mu \mathrm{L}$ of a 4.0 M solution, 1 equiv.). The solution was stirred for 5 minutes then evaporated in vacuo to provide complex 9 $(0.1061 \mathrm{~g}, 0.083 \mathrm{mmol})$ in $96 \%$ yield. $[\alpha]_{\mathrm{D}}^{20}-499\left(c 1.0, \mathrm{CH}_{2} \mathrm{Cl}_{2}\right)$; $\nu_{\max }\left(\right.$ ATR ) 2952, 2906, 2885 and $1622 \mathrm{~cm}^{-1} ; \delta_{\mathrm{H}}(400 \mathrm{MHz}$, $298 \mathrm{~K}): 7.75(4 \mathrm{H}, \mathrm{br}, 4 \times \mathrm{CH}=\mathrm{N}), 7.35(4 \mathrm{H}, \mathrm{br}, 4 \times \mathrm{ArCH}), 6.94$ $(4 \mathrm{H}, \mathrm{br}, 4 \times \mathrm{ArCH}), 3.64\left(8 \mathrm{H}, \mathrm{s}, 4 \times \mathrm{CH}_{2} \mathrm{O}\right), 3.03(4 \mathrm{H}, \mathrm{br}, 4 \times$ $\mathrm{NCH}), 1.61\left(5 \mathrm{H}, \mathrm{br}, \mathrm{OH}+2 \times \mathrm{CH}_{2}\right), 1.5-0.9\left(12 \mathrm{H}, \mathrm{br}, 6 \times \mathrm{CH}_{2}\right)$, $1.28\left(36 \mathrm{H}, \quad \mathrm{s}, \quad 4 \times \mathrm{C}\left(\mathrm{CH}_{3}\right)_{3}\right), 1.18\left(36 \mathrm{H}, \quad \mathrm{s}, \quad 4 \times \mathrm{C}\left(\mathrm{CH}_{3}\right)_{3}\right)$; $\delta_{\mathrm{C}}(100 \mathrm{MHz}, 298 \mathrm{~K}): 164.7$ (br), 161.7, 140.5, 138.8 (br), 130.9 (br), 128.4 (br), 118.1, 67.1, 63.1 (br), 35.5 (br), 34.1, 31.4, 29.3 (br), 26.7 (br), 23.3 (br); $\mathrm{m} / \mathrm{z}\left(\mathrm{FD}^{+}\right)$: found 1158.76381; $\mathrm{C}_{72} \mathrm{H}_{104} \mathrm{~N}_{4} \mathrm{O}_{5} \mathrm{Al}_{2}(\mathrm{M}-\mathrm{Cl} \text {-dioxane })^{+}$requires 1158.76320 .

( $\mu_{2}$-Dioxane)-bis(2,2'-((1R,2R)-cyclohexane-1,2-diylbis (nitrilomethylylidene)) bis(4,6-di-tert-butylphenolato))-di-aluminium chloride 11

1-4 Dioxane $(1 \mathrm{~mL})$ was added to $2,2^{\prime}-((1 R, 2 R)$-cyclohexane-1,2diylbis(nitrilomethylylidene))bis(4,6-di-tert-butyl phenolato)aluminium chloride ${ }^{12}(0.100 \mathrm{~g}, 0.186 \mathrm{mmol})$ in a stoppered oven dried round bottomed flask and the solution left to stir until dissolution. The flask was then attached to a Schlenk line and solvent removed in vacuo to leave compound $11(0.111 \mathrm{~g}$, $0.160 \mathrm{mmol})$ as a yellow solid in $86 \%$ yield. $[\alpha]_{\mathrm{D}}^{20}-567(c 1.0$, $\left.\mathrm{CH}_{2} \mathrm{Cl}_{2}\right) ; \quad \nu_{\max }(\mathrm{ATR}) \quad 2953,2909,2865$ and $1616 \mathrm{~cm}^{-1}$; $\delta_{\mathrm{H}}(400 \mathrm{MHz}, 298 \mathrm{~K}): 8.36(4 \mathrm{H}, \mathrm{br}, 4 \times \mathrm{CH}=\mathrm{N}), 7.59(4 \mathrm{H}, \mathrm{br}, 4 \times$ $\mathrm{ArCH}), 3.86(3 \mathrm{H}, \mathrm{br}, 3 \times \mathrm{NCH}), 3.71\left(8 \mathrm{H}, \mathrm{s}, 4 \times \mathrm{OCH}_{2}\right), 3.19(1 \mathrm{H}$, br, $\mathrm{NCH}), 2.52\left(4 \mathrm{H}, \mathrm{br}, 2 \times \mathrm{CH}_{2}\right), 2.08\left(4 \mathrm{H}, \mathrm{br}, 2 \times \mathrm{CH}_{2}\right), 1.8-1.1$ $\left(8 \mathrm{H}, \mathrm{m}, 4 \times \mathrm{CH}_{2}\right), 1.58\left(36 \mathrm{H}, \mathrm{s}, 4 \times \mathrm{C}\left(\mathrm{CH}_{3}\right)_{3}\right), 1.34(36 \mathrm{H}, \mathrm{s}, 4 \times$ $\left.\mathrm{C}\left(\mathrm{CH}_{3}\right)_{3}\right) ; \delta_{\mathrm{C}}(100 \mathrm{MHz}, 298 \mathrm{~K}): 160.4(\mathrm{br}), 141.2,138.8$ (br), 131.4 (br), 130.8 (br), 127.9 (br), 118.3, 67.2, 63.0 (br), 62.2 (br),
35.7, 34.2, 31.5, 29.9, 27.5, 23.8. $\mathrm{m} / \mathrm{z}\left(\mathrm{FD}^{+}\right)$: found 606.35561; $\mathrm{C}_{36} \mathrm{H}_{52} \mathrm{~N}_{2} \mathrm{O}_{2} \mathrm{ClAl}$ (0.5 M-dioxane) ${ }^{+}$requires 606.35327 .

General procedure for the synthesis of styrene carbonate 13 at 1 bar pressure

A mixture of styrene oxide 12 ( $2 \mathrm{mmol}, 0.23 \mathrm{ml}$ ) and catalyst or catalyst precursor $(2.5 \mathrm{~mol} \%)$ was stirred vigorously in a reaction vial. If the catalyst was being formed in situ, TFA ( $2.5 \mathrm{~mol} \%, 3.83 \mu \mathrm{l}$ or $5 \mathrm{~mol} \%, 7.65 \mu \mathrm{l}$ ) was added; followed in all cases by $\mathrm{Bu}_{4} \mathrm{NBr}(2.5 \mathrm{~mol} \%, 0.0161 \mathrm{~g})$. Upon dissolution, the reaction vial was purged for 5 minutes with $\mathrm{CO}_{2}$ and then fitted with a balloon filled with $\mathrm{CO}_{2}$. The reaction was then stirred at $25{ }^{\circ} \mathrm{C}$ for 24 hours. The unpurified reaction mixture was analysed by ${ }^{1} \mathrm{H}$ NMR spectroscopy to determine the conversion of styrene oxide $\mathbf{1 2}$ into styrene carbonate $\mathbf{1 3}$.

General procedure for the synthesis of styrene carbonate 13 at 50 bar pressure

Styrene oxide 12 ( $2 \mathrm{mmol}, 0.23 \mathrm{ml}$ ) was added to a sample vial preloaded with the desired catalyst $(2.5 \mathrm{~mol} \%)$ and a magnetic stirrer bar. The vial was sealed with a lid pierced by a needle and placed in a high-pressure reactor. The reactor was flushed with $\mathrm{CO}_{2}$, heated to $100{ }^{\circ} \mathrm{C}$ and pressurized to 50 bar with $\mathrm{CO}_{2}$. The reaction was stirred for 24 hours, then the reactor was cooled with a liquid nitrogen bath, before releasing the $\mathrm{CO}_{2}$ pressure. The reaction mixture was dissolved in dichloromethane and filtered through silica to remove catalyst before being analyzed by ${ }^{1} \mathrm{H}$ NMR spectroscopy to determine the conversion. Pure styrene carbonate $\mathbf{1 3}$ was obtained by column chromatography using hexane: EtOAc mixtures $(1: 0,1: 6$, $1: 4,1: 2,1: 1$ and $0: 1)$ as eluent. $\nu_{\max }\left(\mathrm{CH}_{2} \mathrm{Cl}_{2}\right)$ 3078, 3038, 2926, 1784, 1459 and $1064 \mathrm{~cm}^{-1} ;{ }^{1} \mathrm{H}$ NMR $\delta_{\mathrm{H}}(400 \mathrm{MHz}$, $\left.\mathrm{CDCl}_{3}\right)$ : 7.5-7.4 (3H, m, ArH), 7.4-7.3 (2H, m, ArH), $5.67(1 \mathrm{H}$, dd ${ }^{3} J$ 8.1, $7.9 \mathrm{~Hz}$, PhCHO), $4.80\left(1 \mathrm{H}\right.$, dd ${ }^{3} J 8.3 \mathrm{~Hz},{ }^{2} J 8.6 \mathrm{~Hz}$, $\left.\mathrm{CH}_{2} \mathrm{O}\right), 4.34\left(1 \mathrm{H},{ }^{3} J \quad 7.9,{ }^{2} \mathrm{~J} 8.6 \mathrm{~Hz}, \mathrm{CH}_{2} \mathrm{O}\right) ;{ }^{13} \mathrm{C} \quad \mathrm{NMR}$ $\delta_{\mathrm{C}}\left(101 \mathrm{MHz}, \mathrm{CDCl}_{3}\right): 155.0,135.9,129.8,129.3,125.9$, 78.1, $71.3 ; \mathrm{m} / \mathrm{z}\left(\mathrm{ESI}^{+}\right)$: found 187.0369; $\mathrm{C}_{9} \mathrm{H}_{8} \mathrm{O}_{3} \mathrm{Na}(\mathrm{M}+\mathrm{Na})^{+}$requires 187.0366 .

\section{Conflicts of interest}

There are no conflicts to declare.

\section{Notes and references}

1 Privileged Chiral Ligands and Catalysts, ed. Q.-L. Zhou, Wiley-VCH, Weinheim, 2011, ch. 7.

2 K. C. Gupta and A. K. Sutar, Coord. Chem. Rev., 2008, 252, 1420-1450; S. Bellemin-Laponnaz and S. Dagorne, Coordination Chemistry and Applications of Salen, Salan and Salalen Metal Complexes, in Pata's Chemistry of Functional Groups (Metal phenolates), Wiley-VCH, 2012, pp. 263-309. 
3 A. Gualandi, F. Calogero, S. Potenti and P. G. Cozzi, Molecules, 2019, 24, article 1716.

4 Y. N. Belokon, J. Fuentes, M. North and J. W. Steed, Tetrahedron, 2004, 60, 3191-3204; P. U. Naik, G. J. McManus, M. J. Zaworotko and R. D. Singer, Dalton Trans., 2008, 4834-4836; A. Akbari, M. Ahmadi, R. Takjoo and F. W. Heinemann, J. Coord. Chem., 2013, 66, 18661875; M. Behzad, L. S. Ghomi, M. Damercheli, B. Mehravi, M. S. Ardestani, H. S. Jahromi and Z. Abbasi, J. Coord. Chem., 2016, 69, 2469-2481.

5 G. A. Morris, H. Zhou, C. L. Stern and S. T. Nguyen, Inorg. Chem., 2001, 40, 3222-3227; D. Zhu, Z. Su, Z. Mu, Y. Qiu and Y. Wang, J. Coord. Chem., 2006, 59, 409-419; R. M. Haak, A. M. Castilla, M. M. Belmonte, E. C. EscuderoAdán, J. Benet-Buchholz and A. W. Kleij, Dalton Trans., 2011, 40, 3352-3364; E. Martin, M. M. Belmonte, E. C. Escudero-Adán and A. W. Kleij, Eur. J. Inorg. Chem., 2014, 4632-4641.

6 Q. Liu and M. Ding, J. Organomet. Chem., 1998, 553, 179181; G. M. Lombardo, A. L. Thompson, F. P. Ballistreri, A. Pappalardo, G. T. Sfrazzetto, G. A. Tomaselli, R. M. Toscano and F. Punzo, Dalton Trans., 2012, 41, 19511960.

7 A. M. Sargeson and G. H. Searle, Inorg. Chem., 1965, 4, 4552; U. Knof and A. von Zelewsky, Angew. Chem., Int. Ed., 1999, 38, 302-322.

8 V. Vergopoulos, S. Jantzen, D. Rodewald and D. Rehder, J. Chem. Soc., Chem. Commun., 1995, 377-378; D. Agustin, G. Rima, H. Gornitzka and J. Barrau, J. Organomet. Chem., 1999, 592, 1-10; Y. N. Belokon, S. Caveda-Cepas, B. Green, N. S. Ikonnikov, V. N. Khrustalev, V. S. Larichev, M. A. Moscalenko, M. North, C. Orizu, V. I. Tararov, M. Tasinazzo, G. I. Timofeeva and L. V. Yashkina, J. Am. Chem. Soc., 1999, 121, 3968-3973; W. J. Evans, C. H. Fujimoto and J. W. Ziller, Polyhedron, 2002, 21, 16831688.

9 M. North, ARKIVOC, 2012, (i), 610-628.

10 J. A. Castro-Osma, M. North and X. Wu, Chem. - Eur. J., 2014, 20, 15005-15008; X. Wu and M. North, ChemSusChem, 2017, 10, 74-78; P. A. Carvalho,
J. W. Comerford, K. J. Lamb, M. North and P. S. Reiss, Adv. Synth. Catal., 2019, 361, 345-354.

11 J. A. Castro-Osma, M. North, W. K. Offermans, W. Leitner and T. E. Müller, ChemSusChem, 2016, 9, 791-794.

12 M. North, S. C. Z. Quek, N. E. Pridmore, A. C. Whitwood and X. Wu, ACS Catal., 2015, 5, 3398-3402.

13 T. Baronsky, C. Beattie, R. W. Harrington, R. Irfan, M. North, J. G. Osende and C. Young, ACS Catal., 2013, 3, 790-797.

14 M. Sengoden, M. North and A. C. Whitwood, ChemSusChem, 2019, 12, 3296-3303.

15 W. Clegg, R. W. Harrington, M. North and P. Villuendas, J. Org. Chem., 2010, 75, 6201-6207.

16 M. North, P. Villuendas and C. Williamson, Tetrahedron, 2010, 66, 1915-1924.

17 T. Yue, M.-X. Wang, D.-X. Wang and J. Zhu, Angew. Chem., Int. Ed., 2008, 47, 9454-9457.

18 J. Gao, D. Zhu, W. Zhang, G. A. Solan, Y. Ma and W.-H. Sun, Inorg. Chem. Front., 2019, 6, 2619-2652.

19 W. Clegg, R. W. Harrington, M. North and R. Pasquale, Chem. - Eur. J., 2010, 16, 6828-6843.

20 A. W. Addison, N. T. Rao, J. Reedijk, J. van Rijn and G. C. Verschoor, J. Chem. Soc., Dalton Trans., 1984, 13491356.

21 P. L. Gurian, L. K. Cheatham, J. W. Ziller and A. R. Barron, J. Chem. Soc., Dalton Trans., 1991, 1449-1456.

22 H. Sugimoto, C. Kawamura, M. Kuroki, T. Aida and S. Inoue, Macromolecules, 1994, 27, 2013-2018; M.-A. Munoz-Hernandez, M. L. McKee, T. S. Keizer, B. C. Yearwood and D. A. Atwood, J. Chem. Soc., Dalton Trans., 2002, 410-414.

23 CrysAlisPro, Version 1.171.34.41, Oxford Diffraction Ltd.

24 Empirical absorption correction using spherical harmonics, implemented in SCALE3 ABSPACK scaling algorithm within CrysAlisPro software, Version 1.171.34.40, Oxford Diffraction Ltd.

25 O. V. Dolomanov, L. J. Bourhis, R. J. Gildea, J. A. K. Howard and H. Puschmann, J. Appl. Crystallogr., 2009, 42, 339-341.

26 G. M. Sheldrick, Acta Crystallogr., Sect. A: Found. Crystallogr., 2008, A64, 112-122. 